\section{Becky Kgole}

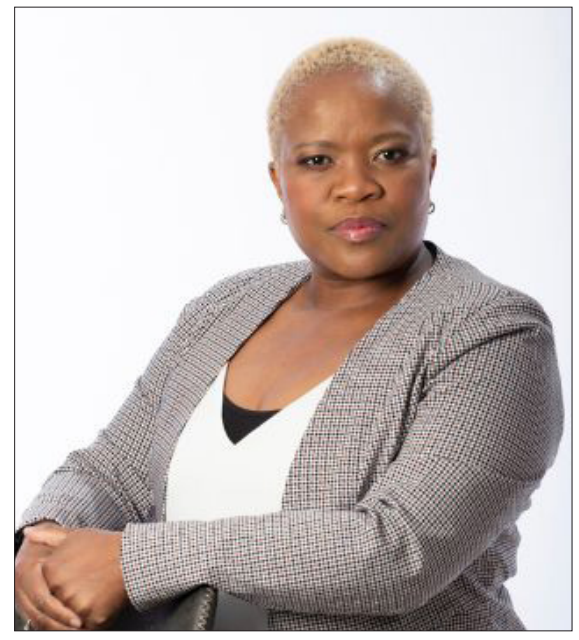

Dr Kgole is a general physician and pulmonologist and head of the clinical unit in internal medicine at Dr. George Mukhari Academic Hospital. She is a lecturer at Sefako Makgatho Health Sciences University, where she is involved in the training of both under-

\section{Ismail Hassan}

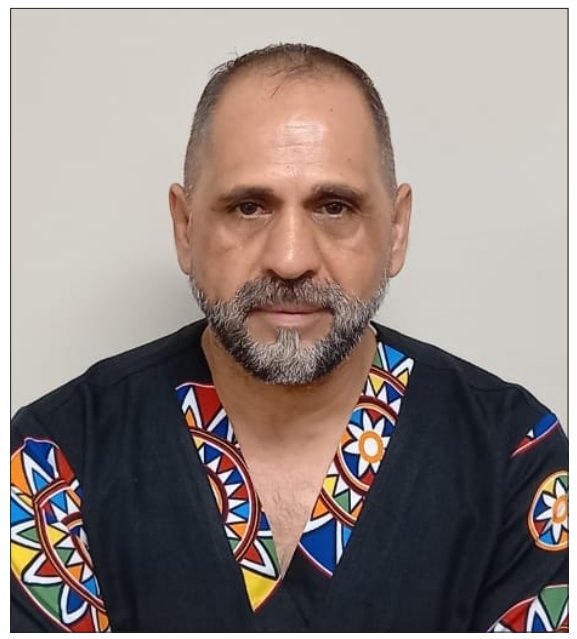

Dr Hassan is a general and respiratory physician at Sefako Makgatho Health Sciences University and Dr. George Mukhari Academic Hospital, where he heads the medical high-dependency/intensive care and postgraduate medical students. Her special interests include critical care and community-acquired pneumonia. Dr Kgole's research is centred on SARS-COV-2 infection and the lung. unit. He is actively involved in the education and training of under- and postgraduate students. Dr Hassan has a special interest in sarcoidosis and he has published on the subject. 


\section{Edson Makambwa}

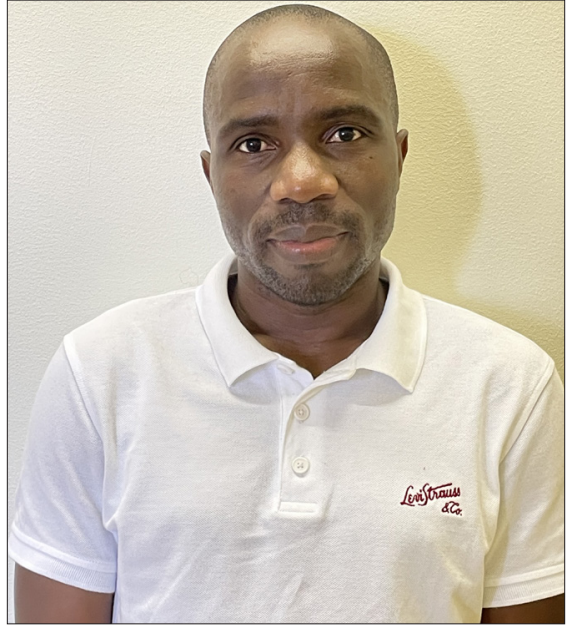

Dr Edson Makambwa graduated with an MB ChB from the University of Zimbabwe in 2005. He trained as a specialist physician at Groote Schuur Hospital (GSH) and the University of Cape Town (UCT), where he was awarded his fellowship in 2018. In
2019, he obtained his MMed from UCT. He is currently completing his subspecialty training in pulmonology and critical care at GSH and UCT. He is involved in tuberculosis (TB) research related to the diagnosis of extrapulmonary TB.

\section{Mohamed Dahim}

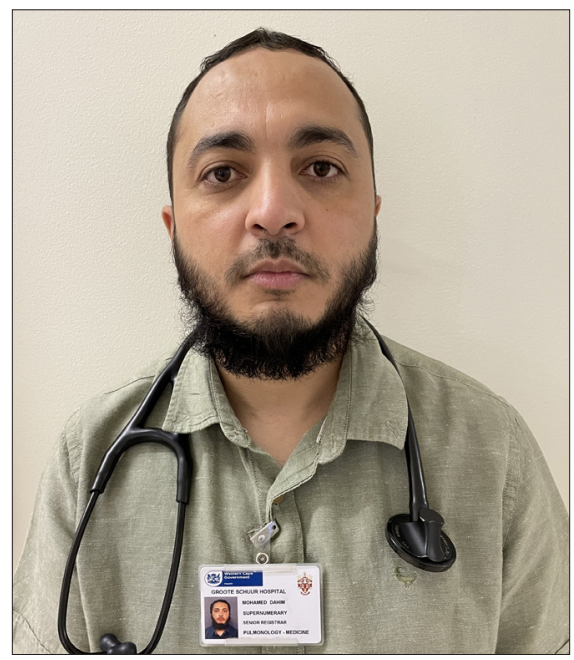

Dr Mohamed Dahim graduated from Tripoli University medical school in 2008. He has worked as a medical officer in medicine and as a lecturer in the Department of Toxicology at Tripoli University. In September 2015, he joined the internal medicine training programme at the Univeristy of KwaZulu-
Natal. He completed his FCP (SA) in 2019 and subsequently his MMed, and joined the Division of Pulmonology in May 2020 at the start of the COVID-19 pandemic! He chose South Africa to do his specialist training, given the highly accredited and globally recognised training programmes. 